\title{
JUDICIALIZAÇÃO DO DIREITO À SAÚDE: REFLEXÃO ACERCA DO FORNECIMENTO DE MEDICAMENTOS NÃO INCLUÍDOS EM ATOS NORMATIVOS DO SUS
}

\author{
JUDICIALIZATION OF THE RIGHT TO HEALTH: REFLECTION ON THE SUPPLY OF \\ MEDICINES NOT INCLUDED IN NORMATIVE ACTS OF THE SUS
}

\section{Urá Lobato Martins}

Doutora em Políticas Públicas e Formação Humanas pela UERJ. Mestra em Direitos Humanos pela UFPA.

E-mail: uramartins@ig.com.br

Recebido em: 15/05/2019

Aprovado em: 14/04/2020

\begin{abstract}
RESUMO: O artigo realiza uma análise crítica sobre a judicialização do direito à saúde, com enfoque para o caso do fornecimento de medicamentos não incluídos em atos normativos do Sistema Único de Saúde (SUS). O artigo tem como objetivo analisar os critérios e parâmetros utilizados pelo Superior Tribunal de Justiça (STJ) com relação ao pedido de fornecimento de medicamentos não incluídos na lista do SUS. Dessa forma, o artigo visa dar resposta às seguintes questões problemáticas: o Poder Público deve ser obrigado a fornecer medicamentos não incluídos na lista do SUS? Qual o posicionamento atual dos Tribunais Superiores a respeito do tema? Quais critérios foram definidos pelo STJ durante o julgamento do Recurso Especial n. ${ }^{\circ}$ 1.657.156-RJ? Para tanto, será feita revisão da literatura com a finalidade de demonstrar as correntes doutrinárias sobre as questões controversas sobre o tema, bem como uma análise dos argumentos e fundamentos contidos no referido julgamento do STJ. Utilizou-se o método hipotético-dedutivo, com pesquisa bibliográfica e documental, através de abordagem qualitativa. Para a coleta e análise das decisões judiciais, utilizou-se como método de procedimento o método do caso norte-americano. Ao final, serão apresentadas reflexões acerca dos critérios e parâmetros utilizados para legitimar a decisão judicial que obrigue o Estado a fornecer medicamentos não incluídos na lista do SUS.
\end{abstract}

Palavras-chave: Direito à saúde; Judicialização; medicamentos; SUS.

ABSTRACT: The article conducts a critical analysis on the judicialization of the right to health, with a focus on the case of supply of medicines not included in normative acts of the Unified Health System (SUS). The article aims to analyze the criteria and use the STJ in relation to the request for the supply of drugs not included in the SUS list. Thus, the article seen in response to the following problematic questions: should the government be obliged to supply drugs not included in the SUS list? What is the current position of the Superior Courts on the subject? What were the criteria adopted by the STJ during the judgment of Special Appeal No. 1.657.156-RJ? To this end, a literature review will be carried out with the possibility of demonstrating clinical instructions on controversial issues on the subject, as well as an analysis of the arguments and grounds contained in the STJ judgment. Use the hypothetical-deductive method, with bibliographic and documentary research, through the qualitative approach. To collect and analyze court rulings, use as a procedural or US case method. In the end, they will be considered reflections on the criteria and used to 
legitimize a judicial decision that is mandatory or the State supplies drugs not included in the SUS list.

Keyword: Right to health; judicialization; medicines; SUS.

SUMÁRIO: Introdução; 1. Judicialização das políticas públicas vinculadas à saúde: análise de questões controversas; 2. Direito à saúde e fornecimento de medicamentos; 2.1 Fornecimento de medicamentos: em busca de parâmetros para viabilizar o acesso ao direito fundamental à saúde; 2.2. Enunciados do Conselho Nacional de Justiça sobre o fornecimento de medicamentos; 2.3 Recurso Especial ${ }^{\circ}$ 1.657.156: requisitos necessários para obrigar o poder público ao fornecimento de medicamentos não incluídos em atos normativos do SUS; Conclusão; Referências.

\section{INTRODUÇÃO}

A judicialização das políticas públicas cresceu nas últimas décadas, sendo que as decisões judiciais estão cada vez mais apresentando novos elementos e argumentos que precisam ter uma análise crítica. No caso, será analisada a política pública vinculada ao direito fundamental à saúde que envolve o fornecimento de medicamentos, tendo sido feito um recorte metodológico, para dar um enfoque mais delimitado ao tema, razão pela qual serão analisados apenas os casos que envolvem fornecimento de medicamentos que não estão incluídos na lista do Sistema Único de Saúde - SUS.

A escolha da temática decorre de sua grande relevância atual. De acordo com o Relatório analítico propositivo intitulado Judicialização da saúde no Brasil: perfil das demandas, causas e propostas de solução (BRASIL, 2019), em 10 anos (2008 a 2017), a judicialização teve um crescimento de $130 \%$, resultando em impactos tano no âmbito público, como também no privado. A referida pesquisa foi realizada pelo Departamento de Pesquisas Judiciárias do Conselho Nacional de Justiça (DPJ/CNJ).

Sabe-se que as pessoas que necessitam recorrer aos Sistema Único de Saúde - SUS, em sua maioria, já sofrem com as desigualdades sociais e econômicas, estando em situação de vulnerabilidade, razão pela qual torna-se necessário pensar em instrumentos que possam servir como uma forma de enfrentamento de tais vulnerabilidades. Nesse contexto, é de vital importância analisar de que forma o Judiciário está se manifestando acerca do fornecimento de medicamentos não incluídos em atos normativos do SUS.

O artigo tem como objetivo analisar os critérios e parâmetros utilizados pelo Judiciário com relação ao pedido de fornecimento de medicamentos não incluídos na lista do SUS. A pesquisa busca responder as seguintes questões problemáticas: o Poder Público deve ser obrigado a fornecer medicamentos não incluídos na lista do SUS? Qual o posicionamento atual dos Tribunais Superiores a respeito do tema? Quais critérios foram definidos pelo Superior Tribunal de Justiça durante o julgamento do Recurso Especial n. ${ }^{\circ}$ 1.657.156-RJ?

Foi utilizado o método hipotético-dedutivo, com pesquisa bibliográfica e documental, através de abordagem qualitativa. Para a coleta e análise das decisões judiciais, utilizou-se como método de procedimento o método do caso norte-americano (case method) ${ }^{1}$. Segundo Ramos e Schorscher (2009, p. 49), o método do caso norte-americano "enfatiza mais a fundamentação que

\footnotetext{
1 “O método do caso, na tradição norte-americana, é um instrumento didático que objetiva o ensino de habilidades voltadas para o desenvolvimento e a prática do raciocínio jurídico por meio de análise de decisões judiciais (...) A idealização e o pioneirismo da utilização desse método no ensino jurídico são atribuídos a Christopher Columbus Langdell, não por ter inventado o aludido método, mas por tê-lo introduzido no ensino universitário do direito por meio do estudo e da discussão dos chamados cases em seu curso de contratos na Harvard Law School." (RAMOS; SCHORSCHER, 2009, p. 49)
} 
embasam a solução proposta do que a resolução do caso em si, embora tenha sofrido alteração em sua conceituação ao longo da história."

A pesquisa jurisprudencial foi realizada no banco de dados do próprio site do STJ. Primeiramente, no campo de pesquisa livre, utilizou-se as seguintes palavras-chave: medicamentos; lista; SUS. Tal busca resultou em 59 (cinquenta e nove) acórdãos, tendo sido selecionado apenas o julgamento proferido no Recurso Especial n. ${ }^{\circ} 1.657 .156-R J$, considerando a delimitação da temática, por ser objeto de recurso repetitivo, tendo gerado o Tema n. 106.

Dessa forma, selecionou-se a decisão proferida pelo Superior Tribunal de Justiça no Recurso Especial n. ${ }^{\circ}$ 1.657.156-RJ, com a finalidade de analisar seus argumentos e fundamentos, gerando, ao final, um esquema dos critérios e parâmetros utilizados no caso de pedido fornecimento de medicamentos que não estão incluídos na lista do SUS.

\section{JUDiCializaÇão das POLÍticas PÚBliCAS VINCULADAS ì SAÚDE: ANÁLISE DE QUESTÕES CONTROVERSAS}

Barroso (2009) destaca que nos últimos anos as normas constitucionais passaram a possuir uma maior aplicabilidade direta e imediata através de juízes e Tribunais, conquistando força normativa e efetividade. Nesse contexto, ganhou destaque a questão do fornecimento de medicamentos, com o fim de viabilizar a promessa constitucional no sentido de prestação de forma universal do serviço referente ao direito à saúde.

No entanto, Barroso (2009) alerta para os casos de condenação do Poder Público ao custeio de tratamentos irrazoáveis ou fornecimento de medicamentos experimentais ou de eficácia duvidosa, vinculados a terapias alternativas. A questão, segundo o referido autor, é que não existia, até então, critério para aferir qual ente federativo deveria ser responsabilizado.

O dilema reside na seguinte questão: deve ser deferido um medicamento a determinada pessoa ou o direito fundamental à saúde é um direito que somente pode ser usufruído de forma coletiva através da implementação de políticas públicas universais? Para Barroso (2009), o excesso de judicialização, em alguns casos, pode gerar prejuízo em detrimento dos demais cidadãos que permanecem dependentes das políticas universalistas a serem implementadas.

A judicialização das políticas públicas pode ser concebida segundo o viés procedimentalista, no sentido de que o direito à saúde depende da implementação das políticas, nos termos do art. 196 da Constituição Federal que diz este direito é "garantido mediante políticas sociais e econômicas". Do lado oposto, a tese substancialista considera que os direitos fundamentais possuem aplicação imediata nos termos do art. $5^{\circ}, \S 1^{\circ}$ da Carta Magna, logo, deve ser garantida sua efetividade.

Cabe ressaltar que o Princípio da Separações dos Poderes (art. $2^{\circ}$ da Carta Magna) não impede que o Judiciário, diante da omissão estatal, interfira para que o cidadão possa ter direto ao direito fundamental à saúde.

De fato, conforme destaca Barroso (2009), o protagonismo do Judiciário pode acabar dando prioridade aos que possuem acesso à Justiça, conhecem seus direitos, refletindo, assim, mais um benefício à classe média do que aos pobres.

Ao analisarem a expansão do poder judicial no âmbito do SUS, Paula, Silva e Bittar (2019) defendem que o processo judicial não seria a via mais adequada para tratar os problemas do SUS, pois, segundo tais autores, nem sempre ocorre a análise do sistema como um todo, razão pela qual "defende-se a via extrajudicial, na qual a participação do Judiciário não é obrigatória para o poder público. Destaca-se ainda que não é prerrogativa dos magistrados deliberar nem ao menos conhecer as políticas do sistema público de saúde" (PAULA; SILVA; BITTAR, 2019, p. 117).

Carvalho (2004), por sua vez, apresenta outras questões para engrandecer o debate acerca da judicialização das políticas públicas no Brasil: 
O uso desses modelos na explicação do comportamento julgador pode servir para elucidar algumas questões, entre elas: quais as forças políticas envolvidas ou em disputa? Em que condições as decisões são tomadas (conjuntura política)? Ocorre influência e/ou pressão externa? Essa pressão surtiu efeito? Os juízes atuam ideologicamente? Ocorreu interferência na aplicação de políticas públicas? (CARVALHO, 2004, p. 124)

O referido autor ressalta, ainda, a questão do grupo de interesses. Dessa forma, para Carvalho (2004), devem ser consideradas tanto as disputas políticas, a conjuntura política, a possibilidade ou não de influência externa, bem como a existência de uma ideologia do julgador, pois não há que se falar em neutralidade ideológica, pois a neutralidade, por si só, já é uma escolha política.

É necessário buscar a maior eficácia social do direito fundamental à saúde. Para Martins (2015), que defende o viés da justiça distributiva, devem ser beneficiados os menos favorecidos, e não apenas uma sociedade que tem com objetivo maximizar o saldo líquido de satisfações.

Quantificar ou relativizar o direito à saúde significa ofender o direito à inviolabilidade de dignidade humana. Se as políticas públicas não asseguram os direitos dos cidadãos em sua totalidade, caberá ao Estado rever suas prioridades e direcionar seus gastos em prol da sociedade, mas tal argumento jamais poderá ser utilizado como óbice para a fruição individual do direito fundamental à saúde (MARTINS, 2015, p. 326).

O ideal, de fato, é que o Judiciário não precise interferir, porém, considerando o contexto brasileiro que apresenta graves distorções históricas sociais e econômicas, a questão da saúde ainda não possui caráter efetivo e universal. E, nesse ponto, retoma-se a questão sobre a fruição do direito à saúde na perspectiva individual ou coletiva. Em regra, a fruição deveria ocorrer de forma coletiva, através de políticas públicas universalizantes e eficientes. Mas quando o sistema falha, o Estado deve ser obrigado a garantir a cada cidadão o acesso ao direito da saúde, dado seu caráter subjetivo.

Logo, a tese de que os casos individuais poderão comprometer o funcionamento SUS revela uma tendência utilitarista, na medida em que, segundo Martins (2015, p. 326), "condiciona um direito individual ao maior saldo líquido de satisfação. Dessa forma, seria necessário utilizar a concepção de justiça distributiva formulada por Rawls, a qual permite a discriminação positiva dos cidadãos em situação menos privilegiada."

O escopo desse artigo é justamente analisar os critérios estabelecidos pelo Superior Tribunal de Justiça sobre o tema (fornecimento de medicamentos que não estão incluídos na lista do SUS), através de decisão proferida em recurso repetitivo, o que será feito nas próximas linhas.

\section{DIREITO À SAÚDE E FORNECIMENTO DE MEDICAMENTOS}

\subsection{Fornecimento de medicamentos: em busca de parâmetros para viabilizar o acesso ao direito fundamental à saúde}

Nos termos do artigo 196 da Constituição Federal de 1988, o direto fundamental à saúde "é direito de todos e dever do Estado, garantido mediante políticas sociais e econômicas que visem à redução do risco de doença e de outros agravos e ao acesso universal e igualitário às ações e serviços para sua promoção, proteção e recuperação."

Uma das diretrizes estabelecidas pela Constituição Federal em seu artigo 198, inciso II, é "o atendimento integral, com prioridade para as atividades preventivas, sem prejuízo dos serviços assistenciais". 
A operacionalidade do SUS foi estabelecida através da Lei $n^{\circ} 8.080 / 90$, com enfoque ao art. $6^{\circ}, \mathrm{I}, \mathrm{d}$, que prevê a execução de ações "de assistência terapêutica integral, inclusive farmacêutica".

Através da Lei n. 12.401/2011 foi incluído o Capítulo VIII no Título II na Lei n. 8.080/1990, estabelecendo regras sobre assistência terapêutica, bem como incorporação de tecnologias em saúde no âmbito do SUS.

Dentre as inovações promovidas pela Lei n. 12.401/2011, cumpre destacar o dispositivo abaixo que trata sobre a necessidade de prescrição médica de acordo com protocolo clínico, sendo que na falta de protocolo, devem ser consideradas as relações de medicamentos instituídas pelo gestor federal do SUS, bem como as listas dos gestores estaduais e municipais do SUS, conforme o caso:

Art. 19-M. A assistência terapêutica integral a que se refere a alínea $d$ do inciso I do art. $6^{\circ}$ consiste em: $\quad$ (Incluído pela Lei $\mathrm{n}^{\circ} 12.401$, de 2011)

I - dispensação de medicamentos e produtos de interesse para a saúde, cuja prescrição esteja em conformidade com as diretrizes terapêuticas definidas em protocolo clínico para a doença ou o agravo à saúde a ser tratado ou, na falta do protocolo, em conformidade com o disposto no art. 19-P; (Incluído pela Lei $\mathrm{n}^{\circ}$ $\underline{12.401, \text { de 2011) }}$

Os procedimentos para incorporar, excluir ou alterar a lista de medicamentos do SUS estão estabelecidos pelo artigo 19-Q da Lei 8.080/1990, devendo ser consideradas evidências científicas e avaliação econômica comparada:

Art. 19-Q. A incorporação, a exclusão ou a alteração pelo SUS de novos medicamentos, produtos e procedimentos, bem como a constituição ou a alteração de protocolo clínico ou de diretriz terapêutica, são atribuições do Ministério da Saúde, assessorado pela Comissão Nacional de Incorporação de Tecnologias no SUS. (Incluído pela Lei ${ }^{\circ} 12.401$, de 2011)

(...)

$\S 2^{\circ}$ O relatório da Comissão Nacional de Incorporação de Tecnologias no SUS levará em consideração, necessariamente: (Incluído pela Lei n ${ }^{\circ} 12.401$, de 2011) I - as evidências científicas sobre a eficácia, a acurácia, a efetividade e a segurança do medicamento, produto ou procedimento objeto do processo, acatadas pelo órgão competente para o registro ou a autorização de uso; (Incluído pela Lei $n^{\circ}$ $\underline{12.401, \text { de 2011) }}$

II - a avaliação econômica comparativa dos benefícios e dos custos em relação às tecnologias já incorporadas, inclusive no que se refere aos atendimentos domiciliar, ambulatorial ou hospitalar, quando cabível. (Incluído pela Lei $\mathrm{n}^{\circ}$ $\underline{12.401, \text { de 2011) }}$

O referido dispositivo estabeleceu que a Comissão Nacional de Incorporação de Tecnologia (CONITEC) deverá assessorar o Ministério da Saúde nas decisões vinculadas à incorporação, exclusão ou alteração de novos medicamentos, produtos e procedimentos, na constituição ou alteração de protocolos clínicos ou diretrizes terapêuticas. Com o advento do Decreto $n^{\circ} 7.646$ de 2011, foi regulamentada a composição, as competências e o funcionamento da CONITEC.

Cabe ressaltar que o artigo 19-T da Lei 8.080/1990 (incluído pela Lei no 12.401, de 2011), veda, em todas as esferas do SUS, pagamento, ressarcimento ou reembolso de medicamento, produto ou procedimento que não seja autorizado pela Agência Nacional de Vigilância Sanitária ANVISA, ou não esteja registrado em tal órgão. 
A Portaria $n^{\circ}$ 3.916/98, do Ministério da Saúde, estabeleceu a Política Nacional de Medicamentos. Na Relação Nacional de Medicamentos Essenciais (RENAME) constam os medicamentos para os tratamentos principais.

Lefèvre (1987) analisou o uso simbólico do medicamento. A seguir, apresenta as duas posições sobre a questão do medicamento:

Nesse sentido, como fazendo parte da luta de classes, no campo da saúde temos, esquematicamente, duas posições com respeito ao medicamento, ambas apoiadas na Ciência: - a inserção do medicamento como um componente da problemática biopsicossocial geradora de estados de saúde e doença, a nível individual e coletivo; - o uso simbólico do medicamento, que permite a obtenção ou reobtenção rápida ou imediata da saúde. (Lefèvre, 1987, p. 65)

Dessa forma, a problemática envolvendo a questão do fornecimento de medicamentos deve considerar a problemática social, as correlações de forças existentes, as condições materiais para fruição de tal direito, considerando a força simbólica destacada pelo referido autor.

Em razão disso, Lefèvre (1987, p. 66) sugere "um duplo campo de pesquisa: a oferta e a procura de mercadorias simbólicas que satisfaçam, em termos sociais, a necessidade, forjada pelas classes dominantes, ou em termos psicológicos, à fantasia, da saúde imediata". No quadro abaixo, os argumentos apresentados pelo autor foram apresentados:

\begin{tabular}{|c|c|}
\hline \multicolumn{2}{|c|}{ DUPLO CAMPO DE PESQUISA } \\
\hline Oferta & Procura \\
\hline $\begin{array}{l}\text { "Este campo de investigação seria teoricamente } \\
\text { amparado por uma sócio semiótica da saúde } \\
\text { imediata que trabalharia, com o instrumental da } \\
\text { sociologia, da antropologia, da semiótica e das } \\
\text { disciplinas da saúde pública, as questões relativas } \\
\text { a produção social da necessidade de "saúde } \\
\text { imediata" e das mercadorias-símbolo } \\
\text { encarregadas de satisfazer esta necessidade. } \\
\text { Neste contexto fica claro que o medicamento é } \\
\text { apenas uma das mercadorias-símbolo possíveis } \\
\text { de serem oferecidas ao consumo." }\end{array}$ & $\begin{array}{l}\text { "Este campo de investigação deve - lançando } \\
\text { mão da psicologia, da psicanálise, da semiótica - } \\
\text { estudar a produção individual do sentido, ou mais } \\
\text { precisamente, as racionalizações que os } \\
\text { indivíduos desenvolvem e que permitem a } \\
\text { internalização das necessidades*, socialmente } \\
\text { geradas, de "saúde imediata". }\end{array}$ \\
\hline
\end{tabular}

Fonte: Quadro elaborado pela autora com base nos dados conceituais propostos por Lefèvre (1987, p. 65 e 66).

Como forma de propor uma solução racional para o tema em questão, Barroso (2009) elaborou alguns critérios e parâmetros que seriam utilizados para justificar a atuação do Judiciário no âmbito das políticas de fornecimentos de medicamentos, os quais estão descritos no quadro abaixo:

\begin{tabular}{|c|c|c|}
\hline \multicolumn{3}{|c|}{$\begin{array}{l}\text { PARÂMETROS PARA RACIONALIZAR E UNIFORMIZAR A ATUAÇÃO JUDICIAL NO } \\
\text { FORNECIMENTO DE MEDICAMENTOS SEGUNDO BAROSO }(2009)\end{array}$} \\
\hline \multirow{2}{*}{$\begin{array}{c}\text { AÇÕES } \\
\text { INDIVIDUAIS }\end{array}$} & Parâmetro & $\begin{array}{r}\text { Argumento } \\
\end{array}$ \\
\hline & $\begin{array}{l}\text { atuação jurisdicional deve } \\
\text { ficar restrita ao fornecimento } \\
\text { dos medicamentos que } \\
\text { constam nas listas elaboradas } \\
\text { pelos entes federativos }\end{array}$ & $\begin{array}{l}\text { Democrático: como os recursos decorrem dos } \\
\text { tributos pagos pelo povo, a decisão de como } \\
\text { gastar deveria ser feita, bem como as prioridades } \\
\text { a serem realizadas, devem ocorrer, } \\
\text { preferencialmente, através de seus representantes } \\
\text { eleitos. }\end{array}$ \\
\hline $\begin{array}{c}\text { AÇÕES } \\
\text { COLETIVAS }\end{array}$ & $\begin{array}{l}\text { a alteração das listas poderia } \\
\text { ser discutida no âmbito de } \\
\text { ações coletivas }\end{array}$ & $\begin{array}{l}\text { Presunção de que os Poderes Públicos fazem a } \\
\text { avaliação necessária ao elaborar as listas dos } \\
\text { medicamentos. Ao Judiciário não caberia refazer }\end{array}$ \\
\hline
\end{tabular}

Revista de Direito Brasileira | Florianópolis, SC | v. 24 | n. 9 | p.68-83 | Set./Dez. 2019 


\begin{tabular}{|c|l|l|}
\hline & & $\begin{array}{l}\text { as escolhas estatais, mas pode agir no caso de } \\
\text { abusos. }\end{array}$ \\
\hline $\begin{array}{c}\text { LEGITIMAÇÃO } \\
\text { PASSIVA }\end{array}$ & $\begin{array}{l}\text { Deve figurar no polo passivo } \\
\text { o ente que é responsável pela } \\
\text { lista referente ao consta o } \\
\text { medicamento objeto da lide. }\end{array}$ & $\begin{array}{l}\text { Deve ser considerada a decisão política já tomada } \\
\text { por cada ente, ao incluir o medicamento em lista. }\end{array}$ \\
\hline
\end{tabular}

Fonte: Quadro possui conceitos elaborados por BARROSO (2009).

Observa-se que Barroso (2009) defende que no âmbito das ações judiciais individuais, o Judiciário deveria intervir apenas para fornecer medicamento que consta nas listas dos entes federativos. Porém, apesar de apresentar argumento democrático relevante, deve-se considerar o caos existente atualmente na política, pois nem sempre os candidatos eleitos seguem as promessas feitas na época eleitoral, motivo pelo qual a legitimidade acaba sendo apenas formal, uma vez que, socialmente, a falta de compromisso dos governos pode tornar inviável o acesso ao direito à saúde para os cidadãos mais carentes. Em regra, caberia aos representantes fazer a escolha de prioridades, mas quando o sistema é omisso, cabe intervenção judicial para fazer valer a efetividade de um direito consagrado constitucionalmente.

Acertadamente, Barroso (2009) defende que no âmbito das ações coletivas, as listas dos entes federativos poderiam sofrer alteração, pois, segundo o autor, embora a escolha estatal não caiba ao Judiciário, a existência de abusos legitima a ação judicial.

Vieira (2008) destaca que através da Suspensão de Tutela Antecipada no 91 o Supremo Tribunal Federal (STF) suspendeu liminar que determinava que o Estado de Alagoas fizesse a aquisição de medicamentos para pacientes transplantados renais e renais crônicos, os quais não foram fornecidos pelo SUS, gerando grande insatisfação, tendo sido considerada restritivas as listas de medicamentos incluídas em tal sistema.

Diante disso, Vieira (2008) ressalta a necessidade de serem estabelecidos critérios claros e adequados, considerado o limite financeiro do Estado, para que haja a incorporação das novas tecnologias. A título de argumentação, a autora faz a seguinte explicação com dados oficiais:

Por exemplo, considere a seguinte situação hipotética, cujo cálculo é muito simples. A prevalência da hepatite viral crônica $C$ no Brasil é estimada em $1 \%$ da população geral. A população brasileira, segundo o Instituto Brasileiro de Geografia e Estatística (IBGE), era de 186.770.562 de pessoas em julho de 2006. Portanto, cerca de 1.867.706 delas possuem o vírus da hepatite C por esta aproximação. Supondo-se que o SUS trate 25\% (466.927) dessas pessoas com o medicamento interferon peguilado e como o tratamento deve ser feito com a aplicação de $180 \mathrm{mcg}$, uma vez por semana durante 48 semanas e, o preço da seringa preenchida de $180 \mathrm{mcg}$ é de $\mathrm{R} \$ 1.107,49$,c o custo estimado é de 24,8 bilhões de reais.

Se esta situação tivesse acontecido, este valor corresponderia a $64 \%$ do gasto total executado pelo Ministério da Saúde em 2006 (38,8 bilhões de reais). Ou seja, dois terços do orçamento federal da saúde seriam gastos para a oferta de um único produto farmacêutico com cobertura de $0,25 \%$ da população (VIEIRA, 2008, p. $3)$.

Além disso, é necessário, segundo a referida autora, assegurar que o medicamento a ser incorporado pelo SUS seja seguro, eficaz e efetivo, atendendo, ainda, ao custo-efetivo, no sentido de escolher a melhor alternativa disponível, no menor custo. E, acrescenta a autora: "também é preciso considerar que o custo de sua incorporação deve ser suportado pela sociedade, frente à necessidade de atender ao conjunto de doenças que acometem a população brasileira como um todo" (VIEIRA, 2008, p. 4). 
No entanto, Vieira (2008) sustenta que o Judiciário não observa esse critério que dá ensejo a uma determinada política pública, "por isso, é mais do que urgente que o Judiciário reconheça que não há meios para garantia do direito à saúde tal qual previsto na Constituição Federal, que não sejam os das políticas" (VIEIRA, 2008, p. 5). Nesse ponto, há um equívoco no raciocínio da autora, pois o Judiciário pode utilizar meios para obter dados técnicos a fim de julgar a lide da melhor forma possível. Pensar de forma contrária, implica em inviabilizar o acesso dos cidadãos ao Judiciário, no caso de patente lesão ao seu direito fundamental à saúde.

Werneck Vianna (2016), por sua vez, também faz severas críticas à judicialização atual da política, mencionado que o Sistema Único de Saúde estaria hoje à margem da República, ficando seu funcionamento dependente de decisões judiciais. Ocorre que o autor precisa contextualizar a questão da saúde e entender os motivos pelos quais as demandas têm crescido. A questão a ser criticada e analisada é por que as demandas no âmbito da saúde têm crescido? É preciso analisar as causas e não apenas as consequências. Isto porque as desigualdades têm cunho estrutural.

Lisboa e Souza (2017) fizeram um estudo sobre o caso das insulinas análogas no Estado da Bahia, segundo os autores, constam na Relação Nacional de Medicamentos Essenciais (RENAME) a insulina humana NPH e a insulina humana regular, no entanto, não ocorreu a inclusão das análogas. A questão é que, segundo tais autores, existe uma ambiguidade nas políticas, "na medida em que uma esfera de governo (o estado, no caso, a Bahia) incorpora à sua lista uma classe de medicamentos, cuja que incorporação não é recomendada pela esfera responsável pela coordenação nacional das políticas (a União)" (LISBOA; SOUZA, 2017, p. 1862).

Por tais motivos, como sugestão, os autores propõem a necessidade de um debate "envolvendo tanto prescritores e gestores da saúde quanto operadores do direito, o Ministério da Saúde, que abriga a Conitec" (LISBOA; SOUZA, 2017, p. 1863).

Catanheide et al (2016) fizeram 53 (cinquenta e três) estudos empíricos sobre a questão da judicialização da questão dos medicamentos no Brasil, tendo visualizado algumas lacunas e pontos pouco esclarecidos. Para os autores "embora vários estudos indiquem que a judicialização favorece indivíduos com boas condições socioeconômicas, há resultados contraditórios, que estão a exigir estudos mais abrangentes". E acrescentam: "de modo similar, não se pode afirmar nem negar que os valores gastos com a compra de medicamentos demandados judicialmente comprometam o orçamento do SUS" (CATANHEIDE et al, 2016, p. 1349).

Pepe, Ventura e Osorio-de-Castro (2011) elaboraram um Manual de Indicadores de Avaliação e Monitoramento das Demandas Judiciais de Medicamentos, tendo formulado trinta indicadores, compostos através de quatro dimensões, quais sejam: 1) Características sociodemográficas do autor da ação judicial - características da população em relação aos aspectos sociais e demográficos; 2) Características processuais das ações judiciais - aspectos que se encontram em conformidade com as leis nacionais e locais; 3) Características médico-sanitárias das ações judiciais - aspectos relativos ao corpo de conhecimentos das Ciências da Saúde e 4) Características político-administrativas das ações judiciais - aspectos relacionados às competências executivas, administrativas e econômicas da Administração Pública, referentes à gestão da Assistência Farmacêutica no Sistema Único de Saúde.

A seguir, será dado enfoque à dimensão n. 4 (quatro): Características políticoadministrativas das ações judiciais - aspectos relacionados às competências executivas, administrativas e econômicas da Administração Pública, referentes à gestão da Assistência Farmacêutica no Sistema Único de Saúde, com a análise do seguinte indicador formulado por Pepe et al (2011):

INDICADOR 4 - Proporção de ações judiciais que demandam ao menos um medicamento que esteja fora dos componentes do bloco de financiamento da assistência farmacêutica

"Conceituação: No conjunto de ações judiciais estudadas, expressa o percentual de ações que demandam ao menos um medicamento que não conste em qualquer componente de financiamento da 
Assistência Farmacêutica (AF), no local e período de estudo. Entende-se por componente do bloco de financiamento da Assistência Farmacêutica as listas de financiamento pactuadas nas instâncias decisórias do Sistema Único de Saúde entre as esferas de governo. A pactuação na Comissão Intergestores Tripartite (CIT) deu origem aos atuais componentes de financiamento: Componente Básico do Bloco de Financiamento da Assistência Farmacêutica, Componente de Medicamentos Estratégicos e o Componente Especializado da Assistência Farmacêutica."

"Interpretação: Expressa, em cada esfera de governo e localidade, a proporção de ações contendo ao menos um medicamento que não faça parte de algum componente de financiamento da Assistência Farmacêutica."

"Plano de análise: Sugere-se, neste indicador, que a frequência relativa do medicamento seja expressa em presente por cada componente do bloco de financiamento da Assistência Farmacêutica e ausente nos componentes do bloco de financiamento."

Fonte: Quando elaborado com base nos critérios propostos por Pepe et al. (2011, p. 54-55).

No entanto, Pepe et al (2001, p. 55) apresenta uma limitação com relação à pesquisa das listas de financiamento pactuadas nas instâncias decisórias do Sistema Único de Saúde, pois argumentam que tais listas "podem variar de acordo com as pactuações nas instâncias decisórias do Sistema Único de Saúde, devendo ser consideradas as listas preconizadas pela esfera federal e também as utilizadas no local do estudo".

Após essa breve revisão de literatura, nas próximas linhas serão apresentados alguns Enunciados do Conselho Nacional de Justiça sobre o tema.

\subsection{Enunciados do Conselho Nacional de Justiça sobre o fornecimento de medicamentos}

Nos dias 18 e 19 de março de 2019, o Conselho Nacional de Justiça (CNJ) promoveu a III Jornada Nacional da Saúde. Na ocasião, foram aprovados 35 (trinta e cinco) enunciados interpretativos que versam sobre o direito à saúde. Dessa forma, a seguir serão apresentados alguns desses enunciados, fazendo uma breve análise crítica sobre os parâmetros utilizados, sendo que alguns deles foram estabelecidos com base nos critérios adotados pelo Superior Tribunal de Justiça, no Recurso Especial. n ${ }^{\circ}$ 1.657.156 que será tratado no item posterior.

Primeiramente, o Enunciado n. 03 trata sobre a forma de averiguar o interesse de agir: "Nas ações envolvendo pretensões concessivas de serviços assistenciais de saúde, o interesse de agir somente se qualifica mediante comprovação da prévia negativa ou indisponibilidade da prestação no âmbito do Sistema Único de Saúde - SUS e na Saúde Suplementar.” (BRASIL, 2019).

Sendo assim, o referido enunciado faz uma condição de ação, na medida em que o autor deve provar a prévia negativa ou a indisponibilidade do serviço ser prestado no âmbito do SUS. A questão é a seguinte: considerando a grande demora no atendimento, será que no momento em que sair essa negativa, ainda dará tempo para proteger o direito da pessoa que recorrer ao judiciário? Qual o parâmetro temporal que se deve aguardar para obter essa negativa?

No caso do Enunciado 06, este foi elaborado com base no Recurso Especial. no 1.657.156, tendo sido estabelecido que "a determinação judicial de fornecimento de fármacos deve evitar os medicamentos ainda não registrados na Anvisa ou em fase experimental, ressalvadas as exceções expressamente previstas em lei” (BRASIL, 2019). Constata-se que este enunciado está em consonância com a Lei 8.080/1990 (com as alterações promovidas pela Lei n 12.401, de 2011).

O Enunciado n. 9 também foi elaborado com base no Recurso Especial. $\mathrm{n}^{\circ}$ 1.657.156, tendo determinado que as ações que tratam sobre medicamentos e tratamentos experimentais "devem observar as normas emitidas pela Comissão Nacional de Ética em Pesquisa - Conep e Agência Nacional de Vigilância Sanitária - Anvisa, não se podendo impor aos entes federados provimento e custeio de medicamento e tratamentos experimentais" (BRASIL, 2019). 
O Enunciado n. 10 foi bem limitativo, no sentido de estabelecer que "o cumprimento de pleitos judiciais que visem à prestação de ações ou serviços exclusivos da assistência social não devem ser impostos ao Sistema Único de Saúde - SUS” (BRASIL, 2019).

Caso o medicamento, produto ou procedimento objeto da lide esteja previsto na lista oficial do SUS ou em Protocolos Clínicos e Diretrizes Terapêuticas - (PCDT), o Enunciado n.11 determina que "o Poder Judiciário determinará a inclusão do demandante em serviço ou programa já existentes no Sistema Único de Saúde - SUS, para o fim de acompanhamento e controle clínico." (BRASIL, 2019).

De forma procedimental, seguindo critérios novamente contidos no Recurso Especial Resp. $n^{\circ} 1.657 .156$, o Enunciado 12 dispõe o seguinte:

ENUNCIADO N ${ }^{\circ} 12$ A inefetividade do tratamento oferecido pelo Sistema Único de Saúde - SUS, no caso concreto, deve ser demonstrada por relatório médico que a indique e descreva as normas éticas, sanitárias, farmacológicas (princípio ativo segundo a Denominação Comum Brasileira) e que estabeleça o diagnóstico da doença (Classificação Internacional de Doenças), indicando o tratamento eficaz, periodicidade, medicamentos, doses e fazendo referência ainda sobre a situação do registro ou uso autorizado na Agência Nacional de Vigilância Sanitária Anvisa, fundamentando a necessidade do tratamento com base em medicina de evidências (STJ - Recurso Especial Resp. $\mathrm{n}^{\mathrm{o}}$ 1.657.156, Relatoria do Ministro Benedito Gonçalves - $1^{a}$ Seção Cível - julgamento repetitivo dia 25.04.2018 Tema 106). (Redação dada pela III Jornada de Direito da Saúde - 18.03.2019) (BRASIL, 2019).

O Enunciado n. 13 menciona ações que envolvam o fornecimento de medicamentos, "recomenda-se, sempre que possível, a prévia oitiva do gestor do Sistema Único de Saúde - SUS, com vistas a, inclusive, identificar solicitação prévia do requerente, alternativas terapêuticas e competência do ente federado, quando aplicável (Saúde Pública e Suplementar)" (BRASIL, 2019).

Com relação à competência, o Enunciado n. 78 delimitou que "compete à Justiça Federal julgar as demandas em que são postuladas novas tecnologias ainda não incorporadas ao Sistema Único de Saúde - SUS" (BRASIL, 2019).

Por fim, um outro Enunciado importante foi o de n. 93 que delimitou um prazo para considerar espera excessiva nas demandas de cidadãos que utilizem o SUS, sendo assim, "considera-se excessiva a espera do paciente por tempo superior a 100 (cem) dias para consultas e exames, e de 180 (cento e oitenta) dias para cirurgias e tratamentos" (BRASIL, 2019).

\subsection{Recurso Especial ${ }^{\circ}$ 1.657.156: requisitos necessários para obrigar o poder público ao fornecimento de medicamentos não incluídos em atos normativos do SUS}

No dia 25 de abril de 2018 o Superior Tribunal de Justiça (STJ) julgou o Recurso Especial o 1.657.156, considerado recurso repetitivo nos termos do art. 1.036 do Código de Processo Civil, tendo como Relator o Ministro Benedito Gonçalves, ocasião em que foram fixados alguns requisitos para que o Poder Público realize o fornecimento de remédios fora da lista do Sistema Único de Saúde (SUS).

Na ocasião, o Superior Tribunal de Justiça decidiu modular os efeitos da decisão, decidindo que "os critérios e requisitos estipulados somente serão exigidos para os processos que forem distribuídos a partir da conclusão do presente julgamento". ${ }^{2}$

\footnotetext{
${ }^{2}$ A modulação está prevista no artigo 927, parágrafo 3º do Código de Processo Civil de 2015: "na hipótese de alteração de jurisprudência dominante do Supremo Tribunal Federal e dos tribunais superiores ou daquela oriunda de julgamento de casos repetitivos, pode haver modulação dos efeitos da alteração no interesse social e no da segurança jurídica".
}

Revista de Direito Brasileira | Florianópolis, SC | v. 24 | n. 9 | p.68-83 | Set./Dez. 2019 
De qualquer forma, a referida decisão é um marco para o direito à saúde, pelo fato de apresentar de forma explícita requisitos que autorizam a intervenção do Judiciário nos casos em que há falha ou omissão do Poder Público em garantir a efetividade ao direito fundamental à saúde.

O caso tratava da situação de uma pessoa que é portadora de glaucoma crônico bilateral (CID 440.1), a qual precisava usar, de forma contínua, os seguintes medicamentos: colírios: azorga $(5 \mathrm{ml})$, glaub $(5 \mathrm{ml})$ e optive $(15 \mathrm{ml})$, conforme prescrição de médico durante atendimento pelo SUS.

O Estado do Rio de Janeiro recorreu da decisão da Corte de origem que deferiu o pedido da paciente, segundo tal Recorrente, não seria cabível fornecer medicamentos em desacordo com os Protocolos Clínicos incorporados ao SUS ou, quando houver protocolo, o fornecimento de medicamentos esteja nas listas editadas pelos entes públicos. No entanto, por unanimidade, foi negado provimento ao recurso do Estado do Rio de Janeiro.

A tese afetada foi a seguinte: "Obrigatoriedade do poder público de fornecer medicamentos não incorporados em atos normativos do SUS (Tema 106)." (BRASIL, STF, Recurso Especial ${ }^{\circ}$ 1.657.156, 2018).

Ao final, foi firmada a seguinte tese, com a atribuição de três requisitos cumulativos para autorizar a concessão de medicamentos não incorporados em atos normativos do SUS:

TESE PARA FINS DO ART. 1.036 DO CPC/2015

A concessão dos medicamentos não incorporados em atos normativos do SUS exige a presença cumulativa dos seguintes requisitos:

(i) Comprovação, por meio de laudo médico fundamentado e circunstanciado expedido por médico que assiste o paciente, da imprescindibilidade ou necessidade do medicamento, assim como da ineficácia, para o tratamento da moléstia, dos fármacos fornecidos pelo SUS;

(ii) incapacidade financeira de arcar com o custo do medicamento prescrito;

(iii) existência de registro na ANVISA do medicamento (BRASIL, STF, Recurso Especial $\left.^{\circ} 1.657 .156,2018\right)$ (grifo nosso).

A seguir, serão expostos e analisados cada um desses critérios e requisitos formulados pelo STJ na referida decisão.

Com relação ao primeiro requisito, verifica-se um requisito procedimental necessário (laudo médico fundamentado e circunstanciado), o qual visa demonstrar que o remédio objeto da lide, é, de fato, imprescindível ou necessário. Além disso, deve ficar comprovada a ineficácia dos medicamentos fornecidos pelo SUS para tratar a doença em questão. Durante o voto Relator o Ministro Benedito Gonçalves, o critério mencionado foi feito em consonância com o Enunciado 15 da I Jornada de Direito da Saúde realizada pelo Conselho Nacional de Justiça em 2014, que assim dispõe:

As prescrições médicas devem consignar o tratamento necessário ou o medicamento indicado, contendo a sua Denominação Comum Brasileira (DCB) ou, na sua falta, a Denominação Comum Internacional (DCI), o seu princípio ativo, seguido, quando pertinente, do nome de referência da substância, posologia, modo de administração e período de tempo do tratamento e, em caso de prescrição diversa daquela expressamente informada por seu fabricante, a justificativa técnica. (BRASIL, 2018)

No caso do segundo requisito, o foco é a questão financeira, devendo ocorrer a comprovação de incapacidade para arcar com os cursos do medicamento, ou seja, segundo o julgamento, deve ser comprovado que a aquisição comprometerá a subsistência do paciente e/ou de seu grupo familiar. Nesse quesito, cabe citar trecho esclarecedor do voto do Relator: "não se exige, pois, comprovação de pobreza ou miserabilidade, mas, tão somente, a demonstração da 
incapacidade de arcar com os custos referentes à aquisição do medicamento prescrito" (BRASIL, STF, Recurso Especial ${ }^{\circ}$ 1.657.156, 2018, p. 23).

No entanto, com relação ao segundo quesito, o conceito de subsistência poderá ficar passível de interpretações diversas, pois se o sistema de saúde deve ser garantido de forma gratuita e universal, existe o risco de o Judiciário diminuir o alcance de uma norma constitucional, vinculando o Poder Público ao fornecimento de medicamento apenas no caso de incapacidade financeira.

Nesse sentido, Medeiros; Diniz e Schwartz (2013) ressaltam que as leis vigentes e as políticas adotadas pelo SUS não realizam o atendimento com base na classe social dos usuários, nem tampouco estipulam limites financeiros com relação aos gastos com o medicamento ora requisitado. Tais autores argumentam que os medicamentos para o tratamento das mucopolissacaridoses (MPS) são considerados um caso paradigmático sobre o tema, visto que tais medicamentos "estão entre os mais caros no cenário da judicialização nacional e têm, cada um, sua produção monopolizada por uma única empresa farmacêutica, além de não terem sido incluídos na política de assistência farmacêutica do SUS até dezembro de 2011." (MEDEIROS; DINIZ E SCHWARTZ, 2013, p. 1090).

Portanto, "O SUS é regido por princípios universalistas e não discrimina o atendimento segundo a classe econômica dos usuários. Com ou sem judicialização, pessoas com capacidade de pagamento podem obter tratamento gratuito sem que isso viole as regras do sistema." (MEDEIROS; DINIZ E SCHWARTZ, 2013, p. 1090).

Nesse ponto, a decisão do STJ poderia ser considerada um ativismo judicial ${ }^{3}$, na medida em que a decisão contraria a legislação e a política adotada pelo SUS baseados nas normas internas, na medida em que o requisito da incapacidade financeira de arcar com o custo do medicamento prescrito seria um elemento novo.

Para Barroso, “a judicialização não decorre da vontade do Judiciário, mas sim do constituinte". No que tange ao ativismo judicial, "este expressa uma postura do intérprete, um modo proativo e expansivo de interpretar a Constituição, potencializando o sentido e alcance de suas normas, para ir além do legislador ordinário" (BARROSO, 2012, p. 31).

Dessa forma, a nova tese fixada pelo STJ, durante o julgamento do Recurso Especial n. 1.657.156, dá um novo sentido aos artigos 196 e 198 da Constituição Federal, os quais não fazem restrição ao acesso ao direito à saúde em função da classe social e econômica, pois o art. 196 é claro ao determinar que "a saúde é direito de todos e dever do Estado, garantido mediante políticas sociais e econômicas que visem à redução do risco de doença e de outros agravos e ao acesso universal e igualitário às ações e serviços para sua promoção, proteção e recuperação" (grifo nosso).

Além disso, esse requisito da capacidade financeira também pode resultar em um efeito reverso, na medida em que pode frustrar o cumprimento de um direito fundamental, pois, às vezes, o valor do medicamento, de forma mensal, não torna inviável a subsistência do paciente, o que dificultaria sua comprovação judicial. No entanto, seu uso prolongado, bem como diversas questões conjunturais que podem ocorrer no decorrer do tempo (como desemprego, perda de um membro provedor, aumento dos gastos por outros motivos, etc), pode mudar a questão da capacidade financeira, uma vez que este conceito não é estático, é dinâmico.

$\mathrm{O}$ último requisito trata da necessidade de registro do medicamento na Agência Nacional de Vigilância Sanitária - ANVISA, nos termos do artigo 19-T, inciso II, da Lei n. 8.080/1991, analisado alhures.

Vislumbra-se, assim, que a decisão judicial ora analisada é importante, pois colocou o direito fundamental à saúde em um patamar superior, dado seu caráter constitucional, perdendo força uma mera formalidade normativa. Logo, o fato de um medicamento não constar na lista dos

\footnotetext{
${ }^{3}$ Sobre as origens do termo "ativismo judicial", recomendo: KMIEC, Keenan D. The origin and current meanings of judicial activism. California: Law Review, 2004.
}

Revista de Direito Brasileira | Florianópolis, SC | v. 24 | n. 9 | p.68-83 | Set./Dez. 2019 
atos normativos do SUS não significa que o paciente não pode recorrer ao Judiciário para obter seu direito. No entanto, exige-se que tal medicamento esteja registrado na ANVISA, nesse quesito, ocorreu uma limitação judicial, no sentido de impedir a concessão de medicamentos ainda não registrados, por vários motivos.

\section{CONCLUSÃO}

A crescente judicialização do direito à saúde demonstra não somente a deficiência estatal, como também revela as mazelas sociais, considerando que as pessoas que necessitam recorrer aos Sistema Único de Saúde - SUS, em sua maioria, já sofrem com as desigualdades sociais e econômicas, estando em situação de vulnerabilidade. Dessa forma, a atuação judicial pode ser uma das formas de enfrentamentos de tais vulnerabilidades.

Neste caso, não há que se falar em ofensa ao Princípio da Separações dos Poderes (art. $2^{\circ}$ da Carta Magna), uma vez que a omissão estatal, por si só, legitima e autoriza a interferência judicial. Em regra, caberia aos representantes fazer a escolha de prioridades, mas quando o sistema é omisso, cabe intervenção judicial para fazer valer a efetividade de um direito consagrado constitucionalmente (MARTINS, 2015).

O dilema sempre ficou em torno de como deve ocorrer a efetivação do direito à saúde, considerando que o excesso de judicialização, segundo Barroso (2009), pode prejudicar os demais cidadãos que permanecem dependentes das políticas universalistas. Considerando que, conforme já apontado por Barroso (2009), o protagonismo do Judiciário pode acabar dando prioridade aos que possuem acesso à Justiça, conhecem seus direitos, refletindo, assim, mais um benefício à classe média do que aos pobres.

De fato, o tema revela várias nuances, disputas políticas, conjuntura política, possibilidade de influência externa, ideologia do julgador (CARVALHO, 2004). Além da questão da força simbólica que envolve o fornecimento de medicamentos (LEFÈVRE, 1987).

É necessário buscar a maior eficácia social do direito fundamental à saúde, seguindo o viés da justiça distributiva, devem ser beneficiados os menos favorecidos, e não apenas uma sociedade que tem como objetivo maximizar o saldo líquido de satisfações. Caso contrário, ocorrerá mera quantificação ou relativização do direito à saúde, violando, assim, a dignidade da pessoa humana (MARTINS, 2015).

O ideal, de fato, é que o Judiciário não precise interferir, porém, considerando o contexto brasileiro que apresenta graves distorções históricas sociais e econômicas, a questão da saúde ainda não possui caráter efetivo e universal. Nesse ponto, retoma-se a questão sobre a fruição do direito à saúde na perspectiva individual ou coletiva. Em regra, a fruição deveria ocorrer de forma coletiva, através de políticas públicas universalizantes e eficientes. Mas quando o sistema falha, o Estado deve ser obrigado a garantir a cada cidadão o acesso ao direito da saúde, dado seu caráter subjetivo.

A questão a ser criticada e analisada é por que as demandas no âmbito da saúde têm crescido? É preciso analisar as causas e não apenas as consequências. As teorias devem servir como instrumento para viabilizar a garantia aos direitos fundamentais, caso contrário, o procedimento e aspectos técnicos ficarão acima da necessidade real e material das pessoas que já estão em situação de vulnerabilidade, em função de sua doença.

Nesse contexto, é de vital importância analisar de que forma o Judiciário está se manifestando acerca do fornecimento de medicamentos não incluídos em atos normativos do SUS. Cabe ressaltar que tramitam no Supremo Tribunal Federal dois Recursos Extraordinários (REs) 566.471 e 657.718, que tratam sobre a questão de fornecimento de medicamentos.

No caso do RE 566.471, no dia 15 de novembro de 2007 o Tribunal, por unanimidade, reconheceu a existência de repercussão geral da questão constitucional suscitada, tendo sido fixado o seguinte tema: "dever do Estado de fornecer medicamento de alto custo a portador de doença grave que não possui condições financeiras para comprá-lo". No dia 11 de março de 2020 o STF, 
por maioria dos votos, negou provimento ao referido recurso, mantendo a decisão recorrida ${ }^{4}$ que foi favorável ao paciente em questão, tendo apreciado o tema 6 da repercussão geral, vencido parcialmente o Ministro Edson Fachin. Em seguida, o Tribunal deliberou que fixaria a tese de repercussão geral em sessão posterior.

No caso do RE 657.718, no dia 18 de novembro de 2011 também foi reconhecida a repercussão geral. Cabe mencionar que no dia 22 de maio de 2019 o STF julgou tal recurso, fixando tese no sentido de que o Estado não pode ser obrigado a fornecer medicamento experimental. Além disso, determinou como regra geral que a inexistência de registro na AVISA é impedimento para fornecer medicamentos, via judicial. Porém, o STF decidiu que será possível a concessão de medicamento sem registro sanitário, em caso excepcional, diante da demora irrazoável da Anvisa na apreciação do pedido de registro, desde que preenchidos os requisitos. ${ }^{5}$

Porém, o presente estudo focou na decisão do Superior Tribunal de Justiça. Dessa forma, através do Recurso Especial ${ }^{\circ} 1.657 .156$, foram estabelecidos alguns critérios para a concessão dos medicamentos não incorporados em atos normativos do SUS, os quais devem ser cumulativos. Com relação ao primeiro requisito, verifica-se um requisito procedimental necessário (laudo médico fundamentado e circunstanciado), o qual visa demonstrar que o remédio objeto da ação é, de fato, imprescindível ou necessário. Além disso, deve ficar comprovada a ineficácia dos medicamentos fornecidos pelo SUS para tratar a doença em questão.

O segundo requisito foca na questão financeira, devendo ocorrer a comprovação de incapacidade para arcar com os cursos do medicamento, ou seja, segundo o julgamento, deve ser comprovado que a aquisição comprometerá a subsistência do paciente e/ou de seu grupo familiar. Por fim, o último requisito trata da necessidade de registro do medicamento na Agência Nacional de Vigilância Sanitária - ANVISA, nos termos do artigo 19-T, inciso II, da Lei n. 8.080/1991.

Considerando que o primeiro e o terceiro requisitos são mais procedimentais e seguem dispositivos já previstos em lei, o segundo requisito que trata sobre a categoria da incapacidade financeira, ao vincular o conceito de subsistência, poderá ficar passível de interpretações diversas. Porém, se o sistema de saúde deve ser garantido de forma gratuita e universal, poderá o Judiciário diminuir o alcance de uma norma constitucional, vinculando o Poder Público ao fornecimento de medicamento apenas no caso de incapacidade financeira? Eis a questão problemática.

Ocorre que as normas vigentes não vinculam o acesso ao atendimento com base na classe social dos usuários, mesmo que fique comprovado que a elite é quem está sendo beneficiada pela judicialização, isto não muda os princípios universalistas do SUS, os quais não discriminam o atendimento, razão pela qual a referida decisão do STJ poderia ser considerada um ativismo judicial, na medida em que a decisão contraria a legislação e a política adotada pelo SUS baseada nas normas internas, na medida em que o requisito da incapacidade financeira de arcar com o custo do medicamento prescrito seria um elemento novo.

Por uma questão de justiça social, seria mais justo que os realmente necessitados tivessem preferência, pois, conforme já mencionado, o judiciário deve considerar as desigualdades sociais e econômica e atuar no sentido de enfrentar e atenuar tais questões. Por outro lado, esse requisito

\footnotetext{
${ }^{4} \mathrm{O}$ Tribunal de Justiça do Estado do Rio Grande do Norte não deu provimento à Apelação do Estado de Rio Grande do Norte, mantendo a sentença recorrida que determinou o fornecimento de medicamento de alto valor, bem como realização de cirurgia em favor do paciente em questão.

5 “1. O Estado não pode ser obrigado a fornecer medicamentos experimentais. 2. A ausência de registro na ANVISA impede, como regra geral, o fornecimento de medicamento por decisão judicial. 3. É possível, excepcionalmente, a concessão judicial de medicamento sem registro sanitário, em caso de mora irrazoável da ANVISA em apreciar o pedido (prazo superior ao previsto na Lei $\mathrm{n}^{\mathrm{o}}$ 13.411/2016), quando preenchidos três requisitos: (i) a existência de pedido de registro do medicamento no Brasil (salvo no caso de medicamentos órfãos para doenças raras e ultrarraras);(ii) a existência de registro do medicamento em renomadas agências de regulação no exterior; e (iii) a inexistência de substituto terapêutico com registro no Brasil. 4. As ações que demandem fornecimento de medicamentos sem registro na ANVISA deverão necessariamente ser propostas em face da União". (BRASIL, STF, 2019)
} 
pode frustrar o cumprimento de um direito fundamental, pois, às vezes, o valor do medicamento, de forma mensal, não torna inviável a subsistência do paciente, o que dificultaria sua comprovação judicial. Porém, seu uso prolongado, bem como diversas questões conjunturais que podem ocorrer no decorrer do tempo (como desemprego, perda de um membro provedor, aumento dos gastos por outros motivos, etc), pode mudar a questão da capacidade financeira, uma vez que este conceito não é estático, é dinâmico. Este é o maior risco, pois ao eliminar o acesso das classes dominantes, a nova orientação pode também inviabilizar o acesso dos mais necessitados, ocasionando um efeito reverso, visto que o critério da capacidade financeira será feito por um intérprete, na medida em que não existem critérios objetivos sobre a questão.

Considerando a decisão proferida no Recurso Especial ${ }^{\circ} 1.657 .156$ é relativamente nova, pois foi proferida no ano de 2018, resta observar como os Tribunais pátrios aplicarão os novos critérios para julgar casos concretos.

\section{REFERÊNCIAS}

BARROSO, Luís Roberto. Da falta de efetividade à judicialização excessiva: direito à saúde, fornecimento gratuito de medicamentos e parâmetros para a atuação judicial. Revista Jurisp. Mineira, Belo Horizonte, a. 60, n $^{\circ}$ 188, p. 29-60, jan./mar. 2009.

BARROSO, Luís Roberto. Judicialização, Ativismo Judicial e Legitimidade Democrática. [Syn]Thesis, Rio de Janeiro, vol. 5, nº 1, 2012, p.23-32.

BORGES, Danielle da Costa Leite. Uma análise das ações judiciais para o fornecimento de medicamentos no âmbito do sus: o caso do Estado do Rio de Janeiro no ano de 2005. Dissertação (Mestrado em Saúde Pública). Ministério da Saúde. Fundação Oswaldo Cruz, Rio de Janeiro, 2007.

BRASIL. Lei $n^{\circ} 8.080$ de 19 de setembro de 1990. Dispõe sobre as condições para a promoção, proteção e recuperação da saúde, a organização e o funcionamento dos serviços e dá outras providências. D.O.U. de 20.9.1990.

BRASIL. MINISTÉRIO DA SAÚDE. Portaria 3.916/GM de 30 de novembro de 1998. Aprova a Política Nacional de Medicamentos.

BRASIL. Conselho Nacional de Justiça - CNJ. Enunciados da I, II e III Jornadas de Direito da Saúde do Conselho Nacional de Justiça. Brasília, 2019. Disponível em: <http://www.cnj.jus.br/files/conteudo/arquivo/2019/03/e8661c101b2d80ec95593d03dc1f1d3 e.pdf>. Acesso em 20 de abril de 2019.

BRASIL. Conselho Nacional de Justiça - CNJ. Relatório analítico propositivo: Judicialização da saúde no Brasil: perfil das demandas, causas e propostas de solução. Brasília: Instituto de Ensino e Pesquisa $\quad-\quad$ INSPER, 2019. $\quad$ Disponível $\quad$ em <http://www.cnj.jus.br/files/conteudo/arquivo/2019/03/66361404dd5ceaf8c5f7049223bdc709 .pdf >. Acesso em 20 de abril de 2019.

BRASIL. Superior Tribunal de Justiça. Recurso Especial $n^{o} 1.657 .156$ - RJ (2017/0025629-7), Relator: Ministro Benedito Gonçalves. Brasília, 25 de abril de 2018 (Data do Julgamento).

BRASIL. Supremo Tribunal Federal. Recurso Extraordinário n. 566471. Relator Atual: Min. Marco Aurélio, Brasília, 2018. 
BRASIL. Supremo Tribunal Federal. Recurso Extraordinário n. 657718. Relator Atual: Min. Marco Aurélio, Brasília, 2019.

CARVALHO, Ernani Rodrigues. Em busca da judicialização da política no Brasil: apontamentos para uma nova abordagem. Revista de Sociologia e Política, Curitiba, n. 23, p. 115-126, Nov., 2004.

CATANHEIDE, Izamara Damasceno; LISBOA, Erick Soares, SOUZA, Luis Eugenio Portela Fernandes de. Características da judicialização do acesso a medicamentos no Brasil: uma revisão sistemática. Physis Revista de Saúde Coletiva, Rio de Janeiro, v. 26, p. 1335-1356, 2016.

LEFÈVRE, Fernando. A oferta e a procura de saúde através do medicamento: proposta de um campo de pesquisa. Rev. Saúde Pública, São Paulo, v. 21, n. 1, p. 64-67, 1987. Disponível em: https://www.scielosp.org/pdf/rsp/1987.v21n1/64-67. Acesso em 09 de maio de 2019.

LISBOA, Erick Soares; SOUZA, Luis Eugenio Portela Fernandes de. Por que as pessoas recorrem ao Judiciário para obter o acesso aos medicamentos? O caso das insulinas análogas na Bahia. Ciência \& Saúde Coletiva, v. 22(6), p. 1857-1864, 2017.

MARTINS, Urá Lobato. A judicialização das políticas públicas e o direito subjetivo individual à saúde, à luz da teoria da justiça distributiva de John Rawls. Revista Brasileira de Políticas Públicas / Programa de Mestrado e Doutorado em Direito do UniCEUB. - vol. 5, número especial. Brasília: UniCEUB, 2015. p. 310-328.

MEDEIROS, Marcelo; DINIZ, Debora; SCHWARTZ, Ida Vanessa Doederlein. A tese da judicialização da saúde pelas elites: os medicamentos para mucopolissacaridose. Ciência \& saúde coletiva. Rio de Janeiro, v. 18, n. 4, p. 1079-1088, Abril 2013. Disponível em: $<$ http://www.scielo.br/scielo.php?script=sci_arttext\&pid=S1413-

$81232013000400022 \& \operatorname{lng}=$ en\&nrm=iso>. Acesso em 03 May 2019.

PAULA, Carlos Eduardo Artiaga; SILVA, Ana Paula da; BITTAR, Cléria Maria Lôbo. Expansão do poder judicial no Sistema Único de Saúde. Rev. Bioética. Brasília , v. 27, n. 1, p. 111119, mar. 2019. Disponível em <http://www.scielo.br/scielo.php?script=sci_arttext\&pid=S198380422019000100111\&lng=pt\&nrm=iso>. Acesso em 13 maio 2019.

PEPE, Vera Lúcia Edáis; VENTURA, Miriam; OSORIO-DE-CASTRO, Claudia Garcia Serpa. (Orgs.). Manual de indicadores de avaliação e monitoramento das demandas judiciais de medicamentos. Rio de Janeiro: Fundação Oswaldo Cruz, Escola Nacional de Saúde Pública Sergio Arouca, 2011. 65p.

RAMOS, Luciana de Oliveira; SCHORSCHER, Vivian Cristina. Método de Caso. In: GHIRARDI, José Garcez (Coord.). Método de ensino em Direito: conceitos para um debate. São Paulo: Saraiva, 2009.

VIANNA, Luiz Werneck. Não há limites para a patológica judicialização da política. Conjur, 2016.

VIEIRA, Fabiola Sulpino. Ações judiciais e direito à saúde: reflexão sobre a observância aos princípios do SUS. Revista de Saúde Pública. 2008. 